\title{
High-Pressure Study of Ion-Molecule Reactions in the Mixture of Carbon Tetrafluoride and Argon
}

\author{
K. BeDERSKI* \\ Institute of Physics, Maria Curie-Skłodowska University, pl. M. Curie-Skłodowskiej 1, 20-031 Lublin, Poland \\ Charge-exchange ion-molecule reactions of $\mathrm{Ar}^{+}$ions with $\mathrm{CF}_{4}$ have been studied in the pressure range 1.33- \\ $39.99 \mathrm{~Pa}$. A quadrupole mass spectrometer with a high-pressure ion source has been used for measuring gaseous \\ ion-molecule reactions in the mixture of $1 \% \mathrm{CF}_{4}$ and $99 \% \mathrm{Ar}$. The fractional abundance $I_{i} / \sum I_{i}$ of the observed \\ $\mathrm{CF}_{3}^{+}, \mathrm{CF}_{2}^{+}$and argon ions has been determined as a function of the gas mixture pressure (at the values of the \\ repeller electrode potentials $V_{\mathrm{R}}$ ranging from 2 to $10 \mathrm{~V}$ ).
}

DOI: $10.12693 /$ APhysPolA.123.896

PACS: $07.75+\mathrm{h}$, 82.30.Fi, 33.15.-e

\section{Introduction}

Dissociative charge-exchange processes in the ionmolecule reactions of rare gas ions with the polyatomic molecules have been studied extensively using several methods [1-12].

These processes in the study of ion-molecule reactions are of fundamental interest. The mechanism in these reactions presents important questions concerning, first, the means by which energy is deposited in the produced ion and the, second, problem of the distribution of energy within the molecule which can lead to molecular fragmentation. From the applied point of view, knowledge of both the product fractional abundance and the reaction rate coefficient is fundamental for the modeling and optimization of plasmas for industrial applications [7].

$\mathrm{CF}_{4}$ is a commonly used gas in radiofrequency (rf) plasmas for etching $\mathrm{SiO}_{2}$ (typically, mixtures of fluorocarbons and argon are used in plasma etching), depositing silicon oxide and silicon nitride layers and for plasma chamber cleaning processes $[1,13-17]$.

The ion-molecule reactions of argon ions with $\mathrm{CF}_{4}$ have been described in papers $[6,8,14,16,18,19]$.

In the present paper, the charge-exchange reactions of argon ions with carbon tetrafluoride molecules have been studied by observing fractional abundance mass spectra in a quadrupole mass spectrometer with a high-pressure ion source. The data are presented as the fractional ratio of the particular reaction product ions and the sum of all product ions $I_{i} / \sum I_{i}$.

\section{Experimental}

The measurements were performed by using of a quadrupole mass spectrometer with a high pressure ion source constructed by the authors [20-23]. The primary

*e-mail: k.bederski@poczta.umcs.lublin.pl ions were produced in the ion source by an electron beam. A gas or a gaseous mixture has been introduced into the ion source ionization chamber, where the gas pressure (controlled by a MKS Baratron capacitance manometer) can be changed from 0.133 to $133 \mathrm{~Pa}$. The positive (relative to the ionization chamber) potential $V_{\mathrm{R}}$ is applied to the ion repeller electrode. The vacuum system of the mass spectrometer is of a differential type and independently evacuates the ion source region (the pumping speed $2000 \mathrm{l} / \mathrm{s}$ ) and the analyzer region (the pumping speed $800 \mathrm{l} / \mathrm{s}$ ). The quadrupole mass spectrometer is able to perform ion analyses in the mass range of 400 a.m.u. The ions are detected by the Balzers electron multiplier. The mass spectrometer was controlled by a computer.

For the experiments performed in this work, the electron energy was $300 \mathrm{eV}$, the ion accelerating voltage $20 \mathrm{~V}$, the gas temperature $297 \mathrm{~K}$, ion repeller electrode potential was changed between 2 and $10 \mathrm{~V}$. The mixture pressure of $1 \% \mathrm{CF}_{4} / 99 \% \mathrm{Ar}$ was varied from 1.33 to $39.99 \mathrm{~Pa}$.

\section{Results and discussion}

In the present experiment the charge-exchange reactions of argon ions with carbon tetrafluoride have been studied at low ion energy in the pressure range 1.33$39.99 \mathrm{~Pa}$. The primary $\mathrm{Ar}^{+}$ions are produced in the mixture of $1 \% \mathrm{CF}_{4}$ and $99 \%$ Ar by the electron impact. The fractional abundance of the secondary $\mathrm{CF}_{3}^{+}, \mathrm{CF}_{2}^{+}$ and argon ions have been determined as a function of gas mixture pressure for nine $(2-10 \mathrm{~V})$ repeller electrode potentials.

The charge-exchange reaction between $\mathrm{A}^{+}$ions and molecules XY can be written as follows:

$$
\mathrm{A}^{+}+\mathrm{XY} \rightarrow \mathrm{XY}^{+}+\mathrm{A} \text {. }
$$

The simple energy balance equation for the charge-exchange reaction (1) is given by [24]:

$$
\mathrm{RE}\left(\mathrm{A}^{+}\right)-\mathrm{IE}(\mathrm{XY})=\mathrm{I}_{\mathrm{nt}} \mathrm{E}\left(\mathrm{XY}^{+}\right)+\mathrm{KE},
$$

where $\mathrm{RE}\left(\mathrm{A}^{+}\right)$is the recombination energy of $\mathrm{A}^{+}$, $\mathrm{IE}(\mathrm{XY})$ is the ionization energy of $\mathrm{XY}, \mathrm{I}_{\mathrm{nt}} \mathrm{E}\left(\mathrm{XY}^{+}\right)$is the product ion internal energy, and $\mathrm{KE}$ is the kinetic energy release. 
If the charge-exchange reaction is dissociative:

$$
\mathrm{A}^{+}+\mathrm{XY} \rightarrow \mathrm{X}^{+}+\mathrm{Y}+\mathrm{A},
$$

then

$$
\begin{aligned}
& \mathrm{RE}\left(\mathrm{A}^{+}\right)-\mathrm{AE}\left(\mathrm{X}^{+}\right)= \\
& \mathrm{I}_{\mathrm{nt}} \mathrm{E}\left(\mathrm{X}^{+}, \mathrm{Y}\right)+\mathrm{KE}\left(\mathrm{A}, \mathrm{X}^{+}, \mathrm{Y}\right) .
\end{aligned}
$$

The dissociative charge-exchange reactions of rare-gas ions with $\mathrm{CF}_{4}$ from thermal energy to $50 \mathrm{eV}$ have been studied by Fisher et al. [6]. They found out the following ion-molecule reactions:

$$
\begin{aligned}
& \mathrm{A}^{+}+\mathrm{CF}_{4} \rightarrow \mathrm{CF}_{3}^{+}+\mathrm{F}+\mathrm{A}, \\
& \mathrm{A}^{+}+\mathrm{CF}_{4} \rightarrow \mathrm{CF}_{2}^{+}+2 \mathrm{~F}+\mathrm{A}, \\
& \mathrm{A}^{+}+\mathrm{CF}_{4} \rightarrow \mathrm{CF}^{+}+3 \mathrm{~F}+\mathrm{A} .
\end{aligned}
$$

$\mathrm{A}^{+}$- the rare-gas ions $\left(\mathrm{Ar}^{+}, \mathrm{Ne}^{+}, \mathrm{He}^{+}\right)$.

The present study results for the reaction $\mathrm{Ar}^{+}+\mathrm{CF}_{4}$ are shown in Fig. 1. The figure shows that the $\mathrm{Ar}^{+} / \mathrm{CF}_{4}$ reaction yields $\mathrm{CF}_{3}^{+}$and $\mathrm{CF}_{2}^{+}$fragments.

$\mathrm{CF}_{3}^{+}$ions are produced by reaction (5) which is exothermic by $1.07 \pm 0.05 \mathrm{eV}[15]$.

The $\mathrm{CF}_{2}^{+}$ions are produced in reaction (6) at higher energies of primary $\mathrm{Ar}^{+}$ions. It is so because the $\mathrm{CF}_{2}^{+}$ fragment ions are formed in an endothermic process, where for $\mathrm{CF}_{2}^{+}$production, the reaction threshold is at $6.55 \pm 0.14 \mathrm{eV}[6]$.

The $\mathrm{CF}^{+}$ions are not detected in the mass spectrum because reaction (7) is highly endothermic (ion repeller electrode potential in the present study was increased up to $10 \mathrm{~V}$ ).

In general, it can be seen in Fig. 1 that $\mathrm{CF}_{3}^{+}$is the main ionic product of ion-molecule reaction (1). This ion shows increase in the fractional abundance at higher values of the gas mixture pressure $\left(I_{i} / \sum I_{i}=0.659\right.$ at $p=39.99 \mathrm{~Pa}$ and $\left.V_{\mathrm{R}}=2 \mathrm{~V}\right) . \mathrm{CF}_{2}^{+}$shows also small increase with the increasing pressure. Due to an endothermic reaction (2) these ions are detected in the mass spectrum when the repeller potential $V_{\mathrm{R}} \geq 8 \mathrm{~V}$. For the product ion $\mathrm{CF}_{2}^{+}$there was observed fractional abundance $I_{i} / \sum I_{i}=0.0597$ (with the pressure $39.99 \mathrm{~Pa}$ and the repeller electrode potential $V_{\mathrm{R}}=10 \mathrm{~V}$ ).

Further experimental and theoretical studies are required in order to compare these results of charge-exchange reactions with those presented in the literature. Very interesting study was performed by Kato and his co-workers [25]. In that study, a computational method of the kinetic model of carbon tetrafluoride $\left(\mathrm{CF}_{4}\right)$ in wet argon gas under the electron beam irradiation was developed.

The results of several other mass-spectrometric studies of ion-molecule reactions carried out in our research group using a high-pressure mass spectrometer are presented in $[23,26-30]$.
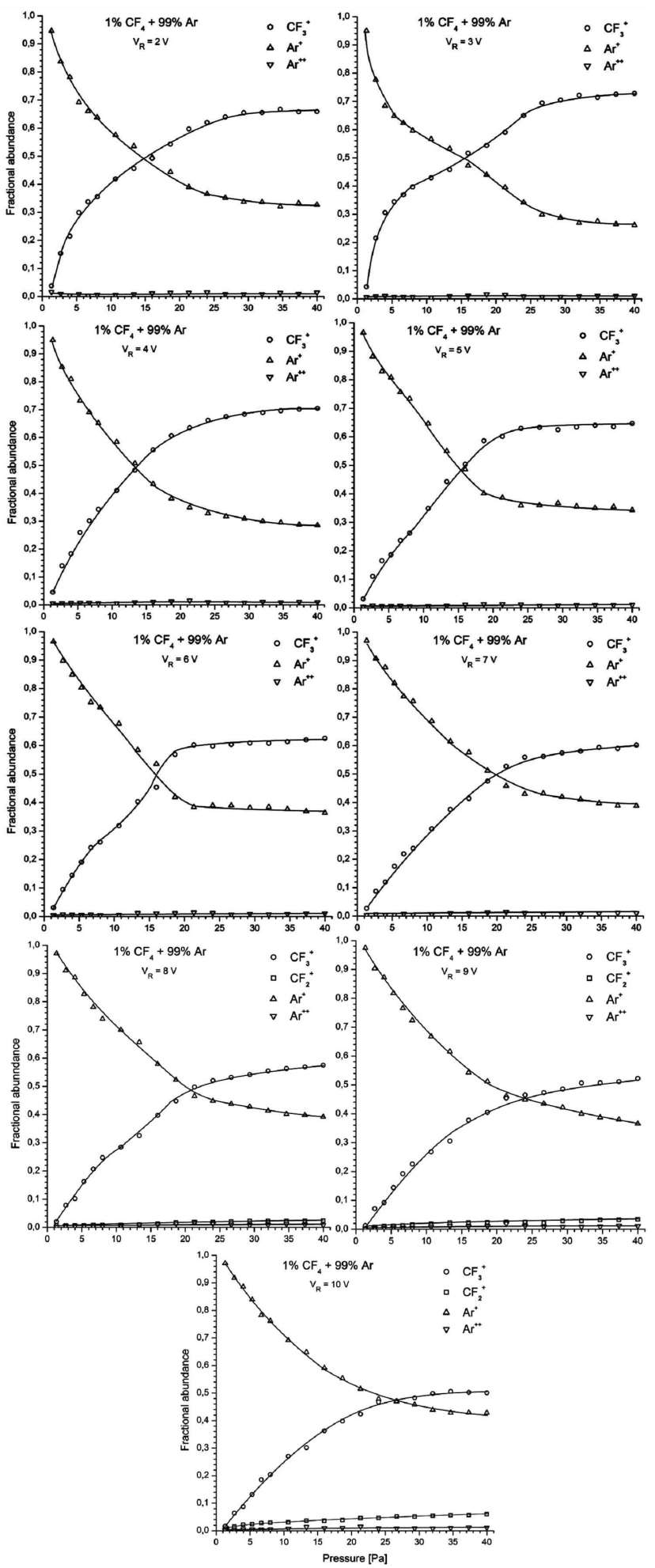

Fig. 1. Fractional abundance of observed ions as a function of pressure in the $1 \% \mathrm{CF}_{4}+99 \% \mathrm{Ar}$ mixture (the repeller electrode potential $V_{\mathrm{R}}=2,3,4,5,6,7,8$, 9 , and $10 \mathrm{~V}$ ). 


\section{Conclusions}

Dissociative charge-exchange reactions of $\mathrm{Ar}^{+}$ions with $\mathrm{CF}_{4}$ have been investigated using a quadrupole mass spectrometer with a high pressure ion source.

The main purpose of the study was to determine fractional abundance of ions produced in the charge-exchange reactions in the carbon tetrafluoride and argon mixture.

The fractional abundance $I_{i} / \sum I_{i}$ of the observed $\mathrm{CF}_{3}^{+}, \mathrm{CF}_{2}^{+}$and argon ions has been determined as a function of the $1 \% \mathrm{CF}_{4}$ and $99 \% \mathrm{Ar}$ gas mixture pressure (in the range $1.33-39.99 \mathrm{~Pa}$ ). The repeller electrode potential was varied over the range $2-10 \mathrm{~V}$. The results obtained in the present study are useful for modeling plasma etching processes and fundamental studies of plasma control.

\section{References}

[1] M.V.V.S. Rao, S.P. Sharma, M. Meyyappan, Plasma Sources Sci. Technol. 11, 397 (2002).

[2] B.L. Peko, I.V. Dyakov, R.L. Champion, M.V.V.S. Rao, J.K. Olthoff, Phys. Rev. E 60, 7449 (1999).

[3] P.B. Armentrout, in: Advances in Atomic, Molecular and Optical Physics, Vol. 43, Eds. B. Bederson, H. Walther, Vol. Ed. M. Inokuti, Academic Press, San Diego 2000, p. 219.

[4] C.-Y. Ng, J. Phys. Chem. A 106, 5953 (2002).

[5] I. Ishikawa, S. Sasaki, K. Nagaseki, Y. Saito, S. Suganomata, Jpn. J. Appl. Phys. 36, 4648 (1997).

[6] R.E. Fisher, M.E. Weber, P.B. Armentrout, J. Chem. Phys. 92, 2296 (1990).

[7] P. Tosi, D. Cappelletti, O. Dmitriev, S. Giordani, D. Bassi, D.R. Lather, M. Smith, J. Phys. Chem. 99, 15538 (1995).

[8] M. Tsuji, M. Furusawa, T. Mizuguchi, T. Muraoka, Y. Nishimura, J. Chem. Phys. 97, 245 (1992).

[9] C. Praxmarer, A. Hansel, W. Lindinger, Z. Herman, J. Chem. Phys. 109, 4246 (1998).

[10] M. Tsuji, Y. Nishimura, H. Ishimi, M. Hisano, H. Oota, J. Chem. Phys. 110, 9064 (1999).
[11] K. Giles, N.G. Adams, D. Smith, J. Phys. B 22, 873 (1989).

[12] P.J. Gale, J.F. Paulson, M. Henchman, Int. J. Mass Spectrom. Ion Proc. 149/150, 529 (1995).

[13] Y. Zhang, G.S. Oehrlein, F.H. Bell, J. Vac. Sci. Technol. A 14, 2127 (1996).

[14] M. Tsuji, T. Funatsu, H. Kuono, Y. Nishimura, J. Chem. Phys. 97, 8216 (1992).

[15] J.H. Futrell, T.O. Tiernan, J. Chem. Phys. 39, 2539 (1963).

[16] M. Tsuji, T. Funatsu, H. Kuono, Y. Nishimura, J. Chem. Phys. 96, 3649 (1992).

[17] Z.L. Petrović, Z.M. Raspopović, V.D. Stojanović, J.V. Jovanović, G. Malović, T. Makabe, J. de Urquijo, Appl. Surf. Sci. 253, 6619 (2007).

[18] M. Chau, M.L. Bowers, Int. J. Mass Spectrom. Ion Phys. 27, 191 (1977).

[19] V. Georgieva, A. Bogaerts, R. Gijbels, J. Appl. Phys. 93, 2369 (2003).

[20] K. Bederski, L. Wójcik, Int. J. Mass Spectrom. Ion Proc. 154, 145 (1996).

[21] L. Wójcik, K. Bederski, Int. J. Mass Spectrom. Ion Proc. 153, 139 (1996).

[22] L. Wójcik, K. Bederski, Int. J. Mass Spectrom. Ion Proc. 127, 11 (1993).

[23] K. Bederski, Vacuum 81, 1374 (2007).

[24] P.R. Kemper, M.T. Bowers, in: Techniques for the Study of Ion-Molecule Reactions, Eds. J.M. Farrar, W.H. Saunders, Jr., Wiley, New York 1988, p. 44.

[25] S. Kato, I. Okuda, E. Takahashi, Y. Matsumoto, Plasma Fusion Res. 3, 038 (2008).

[26] K. Bederski, Vacuum 70, 373 (2003).

[27] K. Bederski, M. Szymańska-Chargot, Vacuum 83, S86 (2009).

[28] K. Bederski, Elektronika 08, 55 (2011) (in Polish).

[29] L. Wójcik, A. Markowski, Vacuum 83, S173 (2009).

[30] A. Markowski, L. Wójcik, A. Gruszecka, Vacuum 83, S178 (2009). 